\title{
Direction in a community of ethical inquiry
}

Tim Sprod

Association for Philosophy in Tasmanian Schools

timsprod3@gmail.com

\begin{abstract}
In response to Hand's paper, I undertake three tasks. Firstly, I believe that his characterisation of the theory and practice of Community of Inquiry facilitation does not take account of approaches to indoctrination and the idea of philosophical selfeffacement that can lessen his worries. Secondly, I will argue that Hand makes some sharp cuts-particularly between justified, controversial and unjustified moral standards - that do not stand up to scrutiny, and that he unnecessarily narrows the scope of moral inquiry. Finally, I will explore the practicalities of these considerations. How should we approach the idea of directive teaching in training facilitators? What should moral inquiry cover? In doing so, I see much of value in Hand's approach, but also recommend some modifications.
\end{abstract}

\section{Key words}

community of moral/ethical inquiry, directive teaching, indoctrination, justified moral standards, philosophical self-effacement

\section{Introduction}

Let me say at the outset that Michael Hand's paper in this issue raises a genuine problem - what should a facilitator of a community of inquiry (CoI) do when the discussion turns to evaluating a moral standard that they firmly believe is fully justified (or, alternatively, totally unjustified)? Moreover, there is much I agree with in what he says and the conclusion he reaches.

One of the difficulties in writing a reply to Hand's thought-provoking paper is that his argument, at important points, rests on assertions that are only properly argued 
for in A Theory of Moral Education, the book on which the paper is based (Hand 2018, henceforth $A T o M E)$. A reader of only Hand's present paper will not have access to those arguments and must take them on trust. I have to warn that another difficulty for that reader will be that my reply, in places, rests on lengthy detailed analysis from my own Philosophical Discussion in Moral Education (Sprod 2001; henceforth PDiME), which I will only be able to summarise briefly here.

I also need to sound a word of warning on Hand's idiosyncratic use of the term moral inquiry. It is much narrower than it might seem on first glance: confined solely to inquiry into the types and strengths of justifications for moral standards. For example, he consigns inquiry into how to negotiate apparently conflicting moral standards, or the application of standards in borderline cases, to moral formation (AToME, p. 35). I suspect that many in the broad philosophy in schools movement would, like me, see such inquiries - and quite a few others - as central to moral inquiry.

This paper is divided into three sections, which consider:

(1) is Hand's characterisation of the state of the theory and practice of CoI accurate? I will contend that it is oversimplified, and that some theoreticians and experienced practitioners have more nuanced understanding that might lessen Hand's concerns.

(2) how sound are Hand's theoretical analyses on which he bases his theory of moral education? I believe that matters are not so clear cut as he argues, and will explain why I think so.

(3) what modifications, if any, might need to be made to Hand's theory in the light of these considerations?

\section{(1) Theory and practice of the community of ethical inquiry}

Central to Hand's paper are three characterisations of CoI theory and practice: '(i) the idea that imparting moral beliefs is indoctrinatory; (ii) the idea that questions discussed in the CoI must be open; and (iii) the idea that teachers in the CoI must be "philosophically self-effacing"' (Hand 2020, p. 8, quoting Sharp 2017). His discussion of (ii) is, I think, very good, as it draws on some excellent modern scholarship from Peter Worley and Laurance Splitter. So I shall confine my remarks to (i) indoctrination, and (iii) philosophical self-effacement. 


\section{Indoctrination}

In his discussion of indoctrination and the CoI, Hand cites only one source (Matthew Lipman, Ann Margaret Sharp and Frederick Oscanyan's 'canonical book' Philosophy in the Classroom 1980). In the 40 years since it was published, many other theorists have addressed indoctrination and the CoI (a few examples: Cam 1994, pp. 19-23; Cam 1995; Splitter \& Sharp 1995, p. 180; Pritchard 1996, p. 109). In PDiME, I devote 12 pages to it (pp. 169-180).

Firstly, let's consider what indoctrination is. Hand's account of indoctrination is, I think, too simplistic. Under his definition, 'to indoctrinate someone is to bring it about that she holds beliefs on some other basis than relevant evidence and argument', it would seem that practically all our moral beliefs are indoctrinated. (It also seems to imply that morality can be a matter of pure reason - 'reliably imparted to others by appealing to their reason alone'. I disagree, but shall not pursue that further here). Generally speaking, that is not how we reach moral beliefs. They are inculcated in us through our immersion in the lifeworld, from when we are tiny babies, by many mechanisms (PDiME, pp. 93-96) - mechanisms that Hand would call moral formation. As we get older, relevant evidence and argument may play a role, but it is virtually never the full story.

Consulting $A T O M E$, we find a more nuanced, but still somewhat confusing, account. Moral formation is 'conative, affective, behavioural, but not cognitive' (p. 35, except when it comes to moral deliberation, which Hand allocates to moral formation, not moral inquiry). Hand does not consider such formation to be indoctrination: 'Worries about indoctrination are not ... pertinent to the enterprise of moral formation. The process of cultivating moral attitudes and dispositions in children cannot itself be indoctrinatory because attitudes and dispositions are not beliefs and therefore not the sorts of things that can be indoctrinated' (AToME, p. 40). He does not explain why he thinks that attitudes and dispositions do not entail beliefs. To say that attitudes and dispositions are completely divorced from beliefs strikes me as wrong - I would say they involve beliefs in action (for the intimate relation of the cognitive with the affective see PDiME, pp. 21-25). Moreover, it would seem to leave social actors who mould children through immersive practices innocent of indoctrination. This sharp split between the conative/affective/behavioural and the cognitive is one example of a number of unwarranted sharp distinctions I shall discuss in section (2).

This stance seems to imply that indoctrination must be carried out entirely cognitively. Yet Hand says 'to indoctrinate someone is to impart beliefs ... non-rationally... [by] 
means of persuasion ... some form of manipulation or psychological pressure' (AToME, p. 6). This sounds to me like (at least partly non-cognitive) moral formationbut with the difference that the beliefs so imparted are ones with which we do not agree. If beliefs can only be imparted cognitively, it seems to me that indoctrination would need to be carried out by presenting rational-sounding arguments that ignore or gloss over fatal, rational objections. We are left with a very narrow scope for indoctrination. Perhaps I am misinterpreting here, but it is not clear to me how Hand sees the relation between the cognitive and the rational. I believe we need a conception of reasonableness (rather than rationality) which includes conative and affective aspects (and others: see PDiME, pp. 14-44).

Theorists have often cited the self-correcting nature of the CoI-that it can turn reflexively on any of its values and reassess them - to avoid the charge of indoctrination (Cam 1994, pp. 19-24; Splitter \& Sharp 1995, p. 180). While there are some problems with this characterisation (PDiME, pp. 170-174), particularly in relation to the taken-for-granted values arising through moral formation, it is the fact that the CoI not only can be self-correcting, but that it provides students with both the wherewithal to assess how they have been brought to certain moral beliefs, and the opportunity to assess those beliefs themselves, in discussion with others. It is this that prevents the CoI being indoctrinatory (PDiME, pp. 174-180).

Secondly, is it true that CoI theorists and practitioners believe that imparting moral beliefs is not permitted? My reading of the literature would lead me to a resounding 'no'. Lipman et al. (1980) say 'a classroom discussion cannot proceed unless there are some implicit or explicit agreements as to ground rules such as "no irrelevant talk will be permitted", "no filibustering", "no use of force" and the like' (p. 87). From here on, theorists insist that certain values - often called procedural (or foundational) values both must underpin the CoI, and are strengthened by it. These are the values that must be observed for a CoI to be able to work properly. What are these values? Gardner (1995, p. 40) for example, lists respect for persons, empathy, impulse control, selfcorrection, courage, patience/perseverance and integrity. García-Moriyón et al. (2020) state that the CoI 'requires - as a necessary precondition-some behaviors based on an attitude of recognition and respect for certain values that are already implicit in every process of sincere dialogue' (p. 2). In PDiME, I discuss these foundational value preconditions at considerable length (see particularly pp. 129-130, pp. 164-165).

Experienced practitioners are aware of the foundational values they are imparting. In a recent article in this journal, Jessica Wang (2020) says ‘By moral education, I do not 
mean "learning about morality" through the explicit instruction of moral precepts or the clarification of moral values. What I mean is 'receiving moral lessons' in a morally stimulating environment, namely, a thinking and caring community of inquiry' ( $\mathrm{p}$. 17). Her empirical work supports the hypothesis that engaging in the CoI strengthens moral values of '[g]oing visiting, learning to put the ego in perspective, ensuring egalitarianism, and practicing linguistic hospitality ... the moral and intellectual ideals that regulate the activities of my classroom community of inquiry' (p. 25).

Of course, these procedural values are somewhat constrained in scope, and do not seem to cover all the values that Hand wishes to be taught directively, which include prohibitions on killing, causing harm, stealing, extorting, lying and cheating; and requirements to treat others fairly, keep promises, and help those in need (AToME, $\mathrm{p}$. 68). There is a prima facie case, then, that CoI theorists have placed an embargo on instilling at least some of these values. To deal with this will have to wait until section (2). Let's turn attention to Hand's third characterisation.

\section{Philosophical self-effacement}

Hand quotes from Sharp (2017, p. 30) and Lipman et al. (1980, p. 186) to claim they believe that guiding students towards an answer to a moral question is not permissible, as that would violate a requirement to be philosophically self-effacing (or substantively neutral). In contrast to this, he argues in favour of directive (but not didactic) teaching in circumstances when a moral standard is known to be justified. There are four notions here that need careful teasing out, before comparing and contrasting them.

Philosophically self-effacing: In the passage Hand quotes, Sharp says 'it is not the role of the facilitator to be giving answers to the philosophical questions that are raised by the group' (Hand 2020, p. 13, my emphasis). I have always taken this admonition (which does commonly appear in CoI literature) to deter teachers from stating their own philosophical (or value) positions outright, especially before the students have a chance to inquire, since the epistemic authority of the teacher means such statements tend to kill discussion. To be self-effacing is to be shy about pushing oneself forward, not to be absent. As Freakly and Burgh (2000) put it: 'Because the process of discussion is in itself educational, it should not be stifled by teachers who present themselves as experts on the content of the subject. This does not mean that teachers should not express their own views in discussion. What it does mean is that they should exercise caution when doing so' (p. 36). 
Substantively neutral: Hand quotes Lipman et al. (1980) making a 'useful' distinction between the process of inquiry and its content (i.e. substance), and urge that teachers should 'normally be neutral' (my italics) on the latter, but insist on maintaining high quality of the former. As we shall see later, and as the word 'normally' implies, this useful process/content distinction is not razor sharp.

Directive vs didactic teaching: Hand gives us a brief outline here of what he means by 'directive teaching'. It is teaching with a direction in mind: 'the aim of persuading pupils that some answer is correct or some conclusion warranted', as contrasted with didactically straight out telling them it is (and, perhaps, why it is). AToME (pp. 37-40) gives us further detail. In an illuminating scenario, Hand contrasts two teachers: Dawn and Tim (no relation). They both hold a certain moral view and both conduct a CoI. Dawn is non-directive. She 'intervenes to maintain order, to ensure that everyone has an opportunity to speak, to request clarifications and to keep the discussion on track ...' Tim is directive; he 'opts to steer the ... discussion ... towards [his] conclusion ... He ensures ... the sound arguments for ... and ... objections to arguments against it, are thoroughly aired and understood ... He does not openly declare his view ... and does [not put] pressure on pupils to adopt his view ...' (p. 38, my italics).

Now, I have to admit that some involved in CoIs - often, but not always, those new to it-have seen philosophical self-effacement and substantive neutrality to require the teacher to be absent in any but a 'traffic cop' role. Hand's quotes from David Kennedy and Karin Murris purport to show that they hold this (though Kennedy's phrases 'at least partially' and 'aspires to', and Murris' "need to "give" their mind to what there is to think about' undermine this interpretation). In an influential paper Inquiry is no Mere Conversation, Susan Gardner (1995, p. 47) argues that '[i]f a community of inquiry is to be successful ... it will require the firm guidance of an ever vigilant facilitator who maintains direction and forces depth with respect to the philosophical truth toward which the inquiry points'.

In more practical terms, Philip Cam (2012) advises teachers that:

Discussion Plans are meant to help provide structure and direction to a discussion and may be designed to direct students' attention to a particular aspect of an issue or possible solution to a problem. Raising some questions that are directive in this sense is distinct from constructing a set of questions that attempt to force students to a predetermined conclusion. That is coercive and runs contrary to the spirit of ethical inquiry. (p. 105, my italics) 
In his study of the beliefs and practices of three expert CoI facilitators, Joe Oyler (2019) identified three guiding principles they held. One was:

To work toward a reasonable judgment [which] reflects a desire to help the group to develop a thoughtful response to their big question. This concern was consistently reflected in the facilitators' explanations of moves and a central belief about the role of dialogue held by all three. This concern represents a desire for more than a high level of argumentation quality or the generation of argument features. It involves pushing deeper into the question or concept to test its limits and implications and go beyond a general survey of opinions on the issue. Facilitators regularly used redirecting, distilling, and paraphrasing to work toward a reasonable judgment. (p. 190, italics in original. The other two guiding principles were Tracking the inquiry and Let the inquiry be student driven).

Here is where the philosophical knowledge of the teacher is deployed: in keeping the discussion on track, ensuring it is doing solid philosophical work. Thus, Dawn's CoI does have a direction, as does the CoI facilitated by the non-declaring (i.e. philosophically self-effacing), non-pressuring (i.e. non-forcing) Tim. Dawn is only non-directive if she treats the discussion as a mere conversation, and does not 'keep it on track' (as some teachers new to CoI do). In PDiME, I have discussed at length this requirement for teachers to engage in what I call pedagogic action (especially pp. 5979, pp. 167-169, pp. 187-188).

The upshot is that Hand's worry about CoI theory ruling out the pursuit of moral truth is based on a misreading of both CoI theory and practice. Nevertheless, insofar as teachers share this misreading-and I agree that some CoI teachers and even trainers do-then arguing against it is an important task.

\section{(2) Hand's theory of moral education}

At the heart of Hand's paper is an assertion that we can allocate moral standards to one of three categories: justified, controversial and unjustified. No argument for this is given in the paper, so again we need to turn to AToME. It is such a central requirement for Hand's theory that he devotes two chapters (32 pages) to supporting it: Chapter 4 on some inadequate justifications, and Chapter 5 to his own solution. 
Much rests on this argument, as not only should members of a CoI be directed so as to agree, rationally, to the justified moral standards (pp. 77-78), but also, their agreement must be on the basis of the justificatory argument Hand runs (p. 89)though he does allow that they might supplement this with some other justification (e.g. religious beliefs). It is not enough that children agree that stealing is wrong, for example, but they must also be able to say - and believe - that the reason why this is the case is precisely the reason that Hand advances. A similar argument holds for unjustified moral standards-children must come to believe, rationally, that these standards are wrong, and wrong for Hand's specific reasons (pp. 84-87). Note that all this requires that all moral educators must also rationally hold the justified moral standards, and hold them for precisely the reasons Hand gives (p. 88).

We might think that if, through a CoI, all members end up agreeing that (say) stealing is wrong, we have moral progress. It could be that some participants are convinced by thinking such a rule leads to the greatest happiness of the greatest number, perhaps, while others hold it is a consequence of treating others always as ends in themselves. For Hand, it seems, moral progress has not been made, for the grounds on which they ought to hold this moral standard are contractarian (AToME, Chapter 5 , pp. 59-75). I do not have room to detail his lengthy argument here, apart from saying that it rests on the solution of the 'problem of sociality' - how we can all live together under conditions of rough equality, limited sympathy and moderate scarcity of resources (p. 60). His solution - the justified acceptance of a set of moral standardshas 'decisive rational force' (p. 59), and is 'not a matter for reasonable disagreement among reasonable people' (p. 69). If I demur from this justification, as I do, then it seems that either my disagreement is unreasonable or that I am an unreasonable person. Holding, as I do, a different meta-ethical theory (discursive virtue ethics, PDiME, pp. 126-142), I might draw the conclusion that I am unfit to be a moral educator.

Perhaps all meta-ethical theories converge on the same set of justified moral standards. Looking at Hand's list (cited above, AToME, p. 68), there might be hope for this-none of them seem terribly controversial. Indeed, AToME discusses this possibility (pp. 55-58) before rejecting it for several reasons, amongst which is that there is overlap but not unanimity. For Hand, only the contractarian argument will do.

Now, let's look a little more closely at the three-fold classification. Can we noncontroversially allocate all purported moral standards into one or other of these 
categories? In order for Hand's argument - that some must be taught directively (and others must not) - to work, such a sharp division is essential. Can such sharp cuts be made?

That question lies at the heart of the matter. Do we agree with John Stuart Mill when he says: 'there ought either to be some one fundamental principle or law, at the root of all morality, or if there be several, there should be a determinate order of precedence among them; and the one principle, or the rule for deciding between the various principles when they conflict, ought to be self-evident' (Mill 1965, p. 278)? Or are we with Aristotle when he says that moral standards 'must be given in outline and not precisely ... [they] have no fixity ... [we] must in each case consider what is appropriate to the situation' (1980, II.2, 1104a1)?

In PDiME (pp. 89-92) I discuss whether ethical theory is monolithic or multidimensional. There are, I think, compelling reasons for believing that moral decisions have multiple inputs, and that there is no universal, fool-proof way to adjudicate between those inputs. For example, Gareth Matthews (1994, Chapter 5) points to five dimensions of moral development:

1. a situated, experiential stock of moral paradigms, gradually enriched with further experience, that forms part of the base for moral intuitions, against which the other dimensions may be measured;

2. an increasing ability to be able to offer defining characteristics for moral terms that take account of their complexity;

3. an increasing ability to judge whether a range of cases (especially borderline ones) fall under a particular moral term;

4. a growing sophistication in the adjudication of apparently conflicting claims, when moral intuitions collide;

5. a heightening of the moral imagination, based in part on increasing understanding of the world and how it works.

(pp. 63-65, my summary)

It is not difficult to see that although, for each person, these dimensions may well converge on an understanding shared with others, and each dimension may come to support the other four in the moral judgements that arise, there is little hope that they 
must all come, in everyone, to a particular determinate position. The hope that they will do so is greatest when the moral statement under consideration is as decontextualised as possible.

Yet to list the moral standards that arise from such intersubjective agreements is merely to list a series of moral rules of thumb-something like Hand's 'prohibitions on killing and causing harm, stealing and extorting, lying and cheating, and requirements to treat others fairly, keep one's promises, and help those in need' (AToME, p. 68). I see no reason why this list has to have sharp boundaries: definite limits to what fits on it and what does not (and I note that, in AToME, Hand nowhere attempts to give a definitive list). Yet for the sharp three-fold classification to work, such a list must be derivable from the theory.

Furthermore, the claim that we can, based on the problem of sociality argument, allocate all purported moral standards unproblematically to one of the three categories is a theoretical one. However, saying that it is a decisively rational argument that all reasonable people accept sounds suspiciously like an empirical claim. John Rawls (1973) makes a similar claim about which characterisation of justice would be chosen from the original position, yet empirical work (e.g. Frohlich, Oppenheimer \& Eavey 1987a, b; Bond \& Park 1991) does not bear this out. I wonder whether Hand's argument would fare any better.

None of this is to say that there is not considerable overlap in lists of those 'rules of thumb' that together form widely accepted moral standards. Hand discusses the work of the (UK) National Forum for Values in Education and the Community (AToME, pp. 44-50), which reaches such consensus. Rather, it is to say that the sharp cut of the (fully) justified from the controversial cannot be made. Indeed, I am rather skeptical about sharp cuts of this sort. See PDiME (pp. 108-119) for discussions of Habermas' (1990, p. 104) sharp cut of the right-i.e. justice-oriented norms, from the good-i.e. evaluative statements about a good life, which can be seen as a parallel to Hand's fully justified/contentious cut. To argue that there is not a sharp cut is not to say that there is no point to such a distinction. Rather, I argue that we can identify 'rightish' rules, which have considerable universality, from 'goodish' ones which are more person or culture dependent (pp. 136-138); in Hand's terms, strongly justified moral standards from somewhat contentious ones. They lie along a continuum, with no sharp boundary. Elsewhere, I similarly argue against any sharp rational/emotional distinction (pp. 19-28), or a sharp procedural value/substantive value distinction (pp. 170-171). 
Seeking consensus on which moral standards are justified, or on whether a particular candidate moral standard is justified, is certainly one of the aims of a community of ethical inquiry. But much of the hard work of morality lies in getting from such a series of useful 'moral rules of thumb' to deciding matters such as exactly what they mean, how they apply in specific contexts, and how apparent inconsistencies between them can be negotiated. This is why I think that moral inquiry needs to be much wider than merely inquiring into the justification of moral standards.

\section{(3) Practical implications of modifications to Hand's theory}

Hand's theory rests heavily on such sharp distinctions: justified from controversial moral standards; moral inquiry from moral formation; the cognitive from the conative/affective/behavioural. Does this mean we need to jettison his theory in toto, and his practical advice to moral educators? I don't think we do.

There do seem to be moral standards concerning which there are very high levels of agreement. These are, as I have mentioned, very decontextualised. Take two examples that Hand mentions: do not steal; keep your promises. In my experience of running CoIs, I cannot recall any session when students came to the conclusion that a moral standard of this sort was incorrect or unjustified. Indeed, I cannot recall even a single student trying to make that argument. Of course, this evidence is anecdotal, and it might be that it is not uncommon for some students to do so: this would need to be tested empirically.

If we accept that there is a continuum of purported moral standards, from those that are very widely accepted, to those that are widely rejected, with varying degrees of controversy along it (little at either end, but quite a bit for those in the middle), what follows?

\subsection{Directive teaching}

It seems to me that our advice to facilitators should be similar to Hand's: when there are strong reasons for subscribing to a moral standard, and compelling objections to a decision to reject it, facilitators should be pedagogically strong in directing the discussion into deep consideration of those reasons and objections. It is best if the students themselves come up with the reasons and objections but, if the CoI seems to be coming to a lazy conclusion through not doing so, the facilitator should act as a 
'devil's advocate' and be directive by injecting the ignored considerations into the discussion (see PDiME, pp. 200-202, where I discuss exactly this situation).

However, our advice might be a little different from Hand's in the case of controversial moral standards. What if the CoI is converging on a lazy acceptance of a controversial moral standard, perhaps through a lack of diversity in the group? Here, too, the facilitator ought to directively ensure that the discussion does not ignore the other side.

Notice here that I am using the term 'directive' in the same sense that Hand does in AToME when discussing teachers Dawn and Tim. Let me quote again: directive teaching 'ensures ... the sound arguments for ... and ... objections to arguments against it, are thoroughly aired and understood ... He does not openly declare his view ... and does [not put] pressure on pupils to adopt his view...' (p. 38, my italics and bold). I need to gloss the bolded word 'it' above: for Hand, 'it' is a justified moral standard; whereas, for me, 'it' is any position advanced in the CoI for which there are sound arguments and sound objections to arguments against it. I note that, for many philosophical questions, there is more than one position like this (and so there are also sound arguments against, and sound objections to, each of them).

Another way of saying this is that the directive teacher 'keep [s] the discussion on track', where the track is heading towards the best supported conclusion. That conclusion may be that a purported moral standard is very strongly justified, or it may be that the standard is controversial, as there seem to be good reasons both for holding it and for rejecting it, and/or there are plausible objections to both holding and rejecting. In the latter case, the conclusion should also be that, since there are reasonable grounds for disagreement, we ought to be respectful of, and tolerant towards, those who have a different view of the status of that purported moral standard.

In other words, the teacher/facilitator should always be directive, but should never try merely to impose their view on the CoI.

\subsection{Moral inquiry}

I would like here to go a little beyond what appears in the paper we are considering. While the distinction between moral inquiry and moral formation receives little attention in Hand's paper, it is presented in the first paragraph and forms an important part of the underpinning for the paper. Let's look at it a little more closely, drawing again on AToME (Chapter 3). Moral inquiry, Hand says, is solely concerned 
with inquiry into the justification for moral standards. It isn't entirely clear whether Hand intends that the CoI should engage solely in such moral inquiry, but he certainly seems to want it to be by far the major element.

Let's return to what happens in actual communities of ethical inquiry. In my experience, it is rare for participants to consider questioning the sorts of moral standards Hand cites. When everyone agrees that (say) stealing is wrong, it is difficult to get discussion going. To get to a worthwhile discussion, we push deeper: why is stealing wrong? Yet to expect a CoI to delve into competing meta-ethical theories, and converge on the sort of contractarian theory Hand runs, is expecting a lot. Maybe more experienced facilitators can do so, but except in more senior classes, I would think that getting participants to identify informally some of the rationales behind competing theories, and to see that they may be in some tension, is about all that can realistically be achieved. After all, if philosophers over several millennia have not agreed on what makes stealing wrong, why should a time-limited CoI of inexperienced schoolkids?

I can, however, report that students who all accept a particular moral standard as justified will often generate animated, deep discussions about related questions, such as:

- Does picking up money from the street and not trying to find the owner, because it seems too difficult, count as stealing?

- Do promises you made a long time ago have to be kept when the circumstances have changed a lot?

- If you promise to get something for someone, and the only way you can keep that promise is to steal the thing, what should you do?

These are matters that Hand has allocated to moral formation, under a 'secondary task' he calls moral deliberation: 'improving children's thinking about the application of their standards' (AToME, p. 35). Hand comments that, in 'the overwhelming majority of cases' it is obvious what the right thing to do is. He asserts that 'borderline cases ... certainly crop up ... but they are the exception rather than the rule' (p. 36). Indeed, he claims that 'disproportionate attention to moral dilemmas and borderline cases can give children the quite misleading impression that moral standards are peculiarly difficult to apply' (pp. 36-37).

I'm not so sure about the 'overwhelming majority', but it is certainly true that there are many straightforward cases. Nevertheless, children - as developing moral agents 
- are still building their moral acuity. As Matthews (1994, cited above) points out, there are multiple dimensions of moral development that require growth in understanding, not merely the one of justification. In PDiME (pp. 91-105), following Aristotle, I discuss the parallel paths of forming good moral habits (which can be seen as parallel to Hand's subscribing to moral standards), and strengthening moral judgement (Aristotle's phronesis, or practical reasoning), which is multi-dimensional.

Thus, as it plays an important part in providing students with the opportunities to strengthen their moral judgement, moral inquiry must go well beyond merely inquiring into the one dimension of the justification for moral standards.

I thank Michael Hand again for a most stimulating paper, which has brought to the fore the vital importance of education for morality - a subject that appears in most curricula only as an add-on to the other disciplines (if that), but which ought to be at the core of any educational system.

\section{References}

Aristotle (1980) The Nicomachean ethics. Oxford University Press, Oxford, UK.

Bond, D \& Park, J-C (1991) An empirical test of Rawls's Theory of Justice: A second approach, in Korea and the United States. Simulation \& Gaming, 22(4), pp. 443462.

Cam, P (1994) A philosophical approach to moral education. Critical \& Creative Thinking, 2(2), pp. 19-26.

Cam, P (1995) Against indoctrination: Response to Davson-Galle. Critical \& Creative Thinking, 3(1), pp. 38-40.

Cam, P (2012) Teaching ethics in schools: A new approach to moral education. ACER, Melbourne, Vic.

Freakley, M \& Burgh, G (2000) Engaging with ethics: Ethical inquiry for teachers. Social Science Press, Katoomba, NSW.

Frohlich, N, Oppenheimer, JA \& Eavey, CL (1987a) Laboratory results on Rawls' distributive justice. British Journal of Political Science, 17, pp. 1-21. 
Frohlich, N, Oppenheimer, JA \& Eavey, CL (1987b) Choices of principles of distributive justice in experimental groups. American Journal of Political Science, 31, pp. 606-636.

García-Moriyón, F, González-Lamas, J, Botella, J, Vela, JG, Miranda-Alonso, T, Palacios, A \& Robles-Loro, R (2020) Research in moral education: The contribution of P4C to the moral growth of students. Education Sciences, 10(119), pp. 1-13. doi: 10.3390/educsci10040119

Gardner, S (1995) Inquiry is no mere conversation (or discussion or dialogue): Facilitation of inquiry is hard work! Critical \& Creative Thinking, 3(2), pp. 102111.

Habermas, J (1990) Moral consciousness and communicative action. MIT Press, Cambridge, MA.

Hand, M (2018) A theory of moral education. Routledge, Abingdon, UK.

Hand, M (2020) Moral education in the community of inquiry. Journal of Philosophy in Schools, (7)2, pp. 4-20.

Lipman, M, Sharp, AM \& Oscanyan, FS (1980) Philosophy in the classroom. Temple University Press, Philadelphia, PA.

Matthews, G (1994) The philosophy of childhood. Harvard University Press, Cambridge, MA.

Mill, JS (1965) Utilitarianism. In JB Schneewind (ed) Mill's ethical writings. Collier, New York, NY.

Oyler, J (2019) Exploring teacher contributions to student argumentation quality. Studia paedagogica, 24(4), pp. 173-198.

Pritchard (1996) Reasonable children: Moral education and moral learning. University Press of Kansas, Lawrence, KS.

Rawls, J (1973) A theory of justice. Oxford University Press, Oxford, UK.

Sharp, AM (2017) Philosophy in the school curriculum. In S Naji \& R Hashim (eds) History, theory and practice of Philosophy for Children: International perspectives. Routledge, London, UK, pp. 30-42. 
Splitter, L \& Sharp, AM (1995) Teaching for better thinking: The classroom Community of Inquiry. ACER, Melbourne, Vic.

Sprod, T (2001) Philosophical discussion in moral education. Routledge, London, UK.

Wang, JC-S (2020) Creating moral winds and nurturing moral growth in a P4C classroom community in Taiwan. Journal of Philosophy in Schools, 7(1), pp. 1637. 